\title{
Interrogative Slifting in English
}

\author{
William Haddican ${ }^{\mathrm{a}, *}$, Anders Holmberg ${ }^{\mathrm{b}}$, Hidekazu Tanaka ${ }^{\mathrm{c}}$, George Tsoulas ${ }^{\mathrm{c}}$ \\ ${ }^{a}$ Department of Linguistics and Communication Disorders, Queens College, CUNY, 65-30 \\ Kissena Blvd. Queens, NY 11367-1597 USA \\ ${ }^{b}$ School of English Literature, Language and Linguistics \\ Percy Building, Newcastle University, Newcastle upon Tyne, NE1 7RU, UK \\ ${ }^{c}$ Department of Language and Linguistic Science, University of York, Heslington, York, YO10 \\ $5 D D, U K$
}

\begin{abstract}
This paper analyzes English "wh-slifting" sentences (for example, How old is she do you think). We argue that these sentences are not scope-marking constructions nor are they derived by simple clausal pied piping as an alternative to wh-extraction. We show that such sentences are akin to declarative slifting sentences, but more restricted than the latter particularly in the kinds of evidential predicates they cooccur with. We argue that the slifted question is not first merged as the complement of the main clause, but that the relationship between the two clauses is mediated by an by an evidential morpheme, which takes the do you think-clause as its specifier. This analysis, which explains several properties of $w h$-slifting that distinguish it from scope-marking constructions and Basque-type clausal pied-piping, partially reconciles $w h$-slifting questions with paratactic approaches to quotative constructions.

Keywords: slifting, wh-movement, embedded root phenomena, pied-piping, scope marking, parenthetical, evidential
\end{abstract}

\section{Introduction}

This paper presents an analysis of sentences like (1) and (2), discussed parenthetically in several sources, but not analysed extensively in any published work as far as we are aware (Ross, 1973; Kayne, 1998; Lahiri, 2002; Reis, 2002; Horvath, 2006). We refer to such sentences as wh-slifting constructions in the spirit of Ross (1973).

${ }^{*}$ Corresponding author. Tel.: +1 718674 4356; fax: +1 7189972873.

Email addresses: bill.haddican@gmail.com (William Haddican), anders.holmberg@newcastle.ac.uk (Anders Holmberg), hidekazu .tanaka@york.ac.uk (Hidekazu Tanaka), george.tsoulas@york.ac.uk (George Tsoulas) 
(1) How old is she, did she say?

(2) Where did John go, do you think?

The main goal of this paper is to argue that sentences such as (1) and (2) are not covert scope marking (partial wh-movement) constructions (pace Horvath 1998; Kayne 1998 and Lahiri 2002), nor instances of embedded clause pied-piping (Ross, 1973). We argue instead that such questions are a species of interrogative slifting constructions, whose membership also includes slifting of yes/no questions as in (3). We show that questions like those in (1)-(3) are akin to declarative slifting sentences, as in (4), but more restricted than the latter particularly in the kinds of evidential predicates that they occur with.

(3) Is Raul coming, do you think?

(4) Max is a Martian, I believe. (Ross, 1973:131)

We argue, contra Ross (1973), that the slifted clause - the question on the left in (1)-(3) - is not first merged as the complement of the main clause, but that the main clause is merged in the specifier position of an evidential head whose complement is the slifted interrogative. Adapting Collins and Branigan's (1997) and Suñer's (2007) analyses of direct quotation structures, we propose that the slifted clause is coindexed with a null operator in the main clause. Different word order possibilities for interrogative slifting constructions - that is, slifting of the entire clause or only a portion thereof - are argued to reflect movement of slifted clause material to a focus position above the evidential phrase. This proposal, which partially reconciles questions like (1)-(3) with quotative constructions, accounts for several word order, binding and presuppositional properties of interrogative slifting constructions that distinguish them from scope marking constructions, Basque-type clausal pied piping constructions as well as declarative slifting sentences.

The discussion is organised as follows. Section 2 considers the viability of two other approaches to questions like (1) and (2) suggested in the literature - complement clause pied-piping, and indirect dependency scope-marking analyses - and argues that neither approach provides an empirically adequate description of the English constructions in (1) and (2). Section 3 compares questions like (1)-(3) to declarative slifting constructions. Section 4 develops a syntactic analysis of interrogative slifting constructions. Section 5 concludes the paper. 


\section{Scope marking and clausal pied piping approaches}

In this section, we consider and ultimately reject two possible analyses of sentences such as (1) and (2) that have been proposed for similar phenomena crosslinguistically. One possibility that we consider is that sentences such as (1) and (2) are cases of finite clause pied piping of the Basque type as analysed by Ortiz de Urbina (1989, 1993) and Arregi (2003) (see also Echeparre, 1997). The possibility of such an analysis for questions like (1) and (2) is raised but not considered in detail by Horvath (2006). In Basque, the pied-piped clause appears in the same left-peripheral position-left adjacent to the main verb-which non-pied-piping wh-phrases also occupy. Examples of clausal pied piping and long wh-movement in Basque are provided in (5) and (6), respectively. ${ }^{1}$

[Se idatzi rabela Jon-ek ] pentzate su?

[what written has Jon-erg] you-think

'What do you think Jon wrote? (Clausal pied piping: Arregi 2003)

(6) Se pentzate su [t idatzi rabela Jon-ek ]?

what you-think [ written has Jon-erg ]

'What do you think Jon wrote?' (Long wh-movement: Arregi 2003)

Ortiz de Urbina (1989, 1993) and Arregi (2003) argue that clausal pied-piping is derived from the same underlying structure that feeds long wh-movement and that the two constructions have the same LFs. Ortiz de Urbina (1993) proposes that the difference between the two structures is feature percolation, that is, that in clausal pied-piping contexts, the relevant $w h$-feature raises out of the wh-phrase to a dominating node - $\mathrm{CP}$ - with the consequence that the whole $\mathrm{CP}$ raises. Below we present evidence against a similar kind of approach to the relationship between whslifting sentences and long wh-movement sentences in English. A second possibility proposed by (Kayne, 1998:174, n.107) and Lahiri (2002) is that sentences such as (1) and (2) are akin to scope marking constructions, which have been discussed in a considerable body of literature on languages including German, Hindi, Hungarian, Passamaquody, Romani, and Warlpiri (Herburger, 1994; Beck, 1996; Lahiri, 2002; Dayal, 2000; McDaniel, 1989; Horvath, 1997, 2000; Bruening, 2004; Legate, 2011). In such constructions, the scope of a wh-word originating in an embedded clause seems to correspond to the surface position of a second wh-phrase in the higher clause - kyaa in the Hindi example in (7) and was in the German example in (8).

\footnotetext{
${ }^{1}$ Arregi's data are from the Ondarroa dialect of Basque (see Arregi, 2003:n. 1)
} 
Raam kyaa soctaa hai [ ki Ramaa-ne kisko dekha ]. Raam what thinks [ that Ramaa-ERG who saw ]

'Who does Raam think that Ramaa saw?' (Hindi: Dayal (2000))

(8) Was glaubt [Hans [ [ mit wem ] [ Jakob jetzt spricht ] ] ]

wh think Hans with whom Jakob now talking

' With whom does Hans think that Jakob is now talking?'

(German: McDaniel (1989))

Two principlal types of approach have been pursued in the recent literature on such sentences. One, the direct dependency approach, takes the higher of the two wh-items to be a non-scope-bearing expletive element; at LF, the lower of the two whitems raises to the matrix $\mathrm{CP}$ to take matrix scope. A consequence of this approach is that long distance wh-questions and scope marking constructions are predicted to have identical LFs and behave similarly in terms of constraints on movement (Beck and Berman, 2000). A second type of account, the indirect dependency approach, takes the higher wh-word not to be an expletive element but rather a wh-quantifier over propositions - the set of possible answers to the matrix question - restricted by the embedded wh-question. On this approach, a sentence like (8) will mean something like "What propositions $\mathrm{p}$, such that $\mathrm{p}$ is a possible answer to "With whom is Jakob talking now?" are such that Hans thinks that p. ${ }^{2}$

The syntactic relationship between the higher wh-phrase and the embedded question is characterized in different ways by different proponents of this analysis. Herburger (1994) and Bruening (2004) propose that the higher wh-phrase is merged as the sister of the lower CP. Horvath (2000) and Lahiri (2002), on the other hand, propose that the lower $\mathrm{CP}$ adjoins to the higher wh-phrase at LF where it provides the restriction for the higher wh-quantifier. In a footnote discussion, (Kayne, 1998:174, n.107) proposes that English sentences like (1) and (2) have a derivation similar to that for Hindi/German scope-marking sentences on some indirect dependency approaches. ${ }^{3}$ Specifically, Kayne proposes that in such sentences, the sister of the matrix verb is a constituent consisting of a null operator and the lower $\mathrm{CP}$, as in (9).

${ }^{2}$ This is also the meaning of the English counterpart of (7) and (8), (i).

(i) What does Hans think? Who is Jakob talking with now?

In German and Hindi the construction is clearly a single complex sentence, though.

\footnotetext{
${ }^{3}$ Lahiri (2002) also suggests that these sentences might be analysed as scope-marking sentences but does not spell out a proposal.
} 
The operator will be a silent version of German was and Hindi kyaa in the above examples.

$$
\mathrm{V}[\mathrm{Op}[\mathrm{CP}]]
$$

Kayne proposes that the null wh-operator in (9) moves to the left periphery of the matrix clause. At this point in the derivation, the structure will resemble the surface orders in Hindi and German partial wh-movement sentences as in (7) and (8), on approaches that take the two wh-phrases to be generated as a constituent (Herburger, 1994; Bruening, 2004). The English construction in (1) and (2) will however differ from "overt" scope marking languages like German and Hindi in two key ways: first, the higher wh-operator will be silent in English but not German/Hindi; and second, the English sentences will involve an additional overt movement step that will raise the lower clause to the left periphery of the matrix clause. This derivation is illustrated in (10).

$$
[\mathrm{CP}[\mathrm{Op}[\ldots \mathrm{V}[<\mathrm{Op}>[<\mathrm{CP}>]]]]]
$$

Superficially, English sentences such as (1) and (2) appear more closely akin to Basque sentences such as (5) in that they involve overt clausal movement to the left periphery of the main clause and have no overt additional $w h$-word. In the following discussion, we review five sets of facts about wh-slifting sentences in English, which suggest that neither a clausal pied-piping approach nor a scope marking approach is empirically adequate.

\subsection{Presuppositions of the raised clause}

A first problem for a pure clausal pied-piping account concerns presuppositions of the raised clause. Herburger (1994) notes that (7) presupposes that Raamaa actually saw someone, unlike in counterpart long wh-movement questions. English behaves similarly. Consider, for example, a context in which (11) has just been uttered.

(11) John didn't go anywhere, but Mary thinks that he went somewhere.

In this context, (12) (with stress on think) but not (13) (with any stress pattern) will be a felicitous response.

(12) Where does she THINK John went?

(13) \#[Where did John go] does she think?

In contrast, Arregi reports that the Basque example in (14) does not presuppose that Jon actually killed someone. 


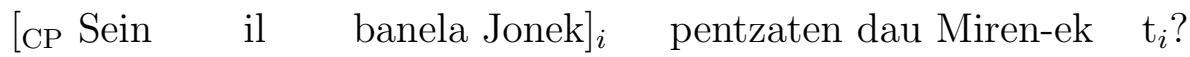
[CP who.ABs killed had Jon-ERG $]_{i}$ thinks aux Miren-ERG $\mathrm{t}_{i}$ 'Who does Miren think Jon killed?'

Arregi (2003)

In terms of presuppositions of the raised clause, then, English wh-slifts behave like scope marking constructions and unlike Basque clausal pied piping.

\subsection{Selecting bridge verbs/predicates}

Lahiri (2002) notes that in Hindi, the set of bridge verbs/predicates available in scope marking constructions is smaller than those that typically allow for whextraction, and are restricted to a handful of verbs of saying and cognition (Lahiri, 2002:517). Similarly, English wh-slifting questions are fully natural only with a similarly limited set of verbs (think, believe, suppose, suspect), and marginal with predicates like claim and be possible that happily tolerate long wh-movement as illustrated in (15)-(18).

*[Which book did she steal] is it possible?

Which book is it possible that she stole?

??[What did the robbers take] do you claim?

What do you claim that the robbers took?

This contrast is again problematic for the clausal pied piping approach, which predicts no selectional differences between the two constructions if they are derived from the same underlying structure and share a common LF. Restrictions on the sets of main clause predicates that allow wh-slifting are discussed in detail in section 4.

\subsection{Negation}

Wh-slifting questions also differ from long wh-movement questions in their sensitivity to sentential negation in the higher clause. While long wh-movement is fine across negation, wh-slifting is blocked, as illustrated in (19).

a. Who don't you think/do you not think [ < who $>$ will come ]?

b. *[ Who will come ] don't you think/do you not think?

In this respect, wh-scope marking constructions again behave similarly. As noted by Rizzi (1992) and in much subsequent literature, wh-scope marking constructions

are generally poor when the higher clause contains sentential negation, unlike counterpart long wh-movement constructions (Horvath, 1997; Beck and Berman, 2000; 
Dayal, 2000; Arregi, 2003; Bruening, 2004). We illustrate this with the German example in (20) from Dayal (1993).
a. *Was glaubst du nicht, mit wem Maria gesprochen hat? what believe you not with whom Maria talked has
b. Mit wem glaubst du nicht, dass Maria gesprochen hat? with whom believe you not that Maria talked has 'Who don't you think that Maria talked to?'

Beck (1996) proposes that the contrast in (20) is a consequence of a filter that blocks LF movement, but not overt movement, across a negative quantifier, the Minimal Negative Structure Constraint (MSNC). On direct and indirect scope marking approaches, this constraint is violated when the wh-phrase in the lower clause raises at LF to the position of was in the higher clause. The long wh-movement sentence in (20b) does not run afoul of this filter since raising of the relevant wh-phrase is overt. Note that in (19), the clause containing the wh-phrase raises past negation overtly, so this movement cannot be the source of the degradation of (19b) on Beck's approach. However, recall that, on Kayne's (1998) analysis in (9), the silent operator raises to the left periphery of the matrix clause. If, contra Kayne (1998), we take this movement to be at LF, then (19b) is correctly excluded on Beck's approach.

The contrast in (19) is more problematic for a "simple" clausal pied-piping approach (i.e. without null operator movement), which predicts similar derivations and LFs for the two kinds of structures. In fact, Arregi (2003) shows that Basque clausal pied-piping constructions are similarly constrained: while long distance whmovement is possible across sentential negation in a higher clause, clausal pied-piping is poor.
a. * ${ }_{\mathrm{CP}}$ Sein jun danik $]$ es tau esan Miren-ek $t_{\mathrm{CP}}$ ? [CP who gone has ] not has said Miren-erg $t_{\mathrm{CP}}$ 'Who didn't Miren say left?'
b. Sein $n_{1}$ es tau esan Mirenek [CP $t_{1}$ jun danik $]$ ? Who $_{1}$ not has said Miren-erg [CP $t_{1}$ gone has ] 'Who didn't Miren say left?'

Arregi (2003)

Arregi also explains the contrast in (21) in terms of Beck's MNSC. In particular, Arregi proposes that pied-piped clauses such as (21) involve LF extraction of the whword to the left periphery of the matrix clause where it scopes, followed by obligatory reconstruction of remnant $\mathrm{CP}$. In sentences like (21b), these assumptions will mean that the negative morpheme es will intervene between the wh-word in the matrix 
$\mathrm{CP}$ and its reconstructed trace, in violation of Beck's proposed filter. An obstacle to extending this approach to the English wh-slifting contrast in (19) comes from the absence of condition $\mathrm{C}$ violations in English, suggesting that the preposed clause does not obligatorily reconstruct. In the well-formed example in (22), the R-expression John is coindexed with a pronoun in the matrix clause, suggesting that John is not c-commanded by the pronoun at LF. This fact seems to indicate that the preposed clause in English does not obligatorily reconstruct unlike in Arregi's proposal for Basque.

[What did $\mathrm{John}_{i}$ buy ] did he say? $^{2}$

The effect of negation in questions like (19) therefore remains problematic for a clausal pied piping or direct dependency approach to English wh-slifting, which takes wh-slifting and long wh-movement to have similar derivations and LFs.

\subsection{Root clause properties}

The three sets of properties of wh-slifting just discussed are all consistent with analyses of scope marking constructions found in the literature. These properties of scope-marking constructions in German and Hindi especially, have all in fact been cited in favour of an indirect dependency approach in much of the literature discussed above. Again, the fact that these properties suggest a different LF or syntactic differences between long wh-movement and scope marking constructions makes a direct dependency approach to these constructions problematic. Nevertheless, two additional properties of wh-slifting, which we describe in the following discussion, are predicted by neither clausal pied-piping nor scope-marking approaches. A first such property of $w$-slifting constructions is the root-clause behaviour of the slifted question. As noted by Lahiri (2002), subject auxiliary inversion (SAI) is obligatory in both clauses in non-subject wh-questions.

[ How old is she ] do you think?

$$
\begin{array}{lr}
*[\text { How old she is }] \text { do you think? } & \text { (no SAI in lower clause) } \\
*[\text { [How old }] \text { is she }] \text { you think? } & \text { (no SAI in upper clause) }
\end{array}
$$

SAI does not apply in the embedded clause in long wh-movement contexts:

*How old do you claim is she?

In contrast, German scope marking constructions are not root-clause-like in word order. (27) shows that the lower clause in scope-marking constructions cannot have 
main clause verb-second (V2) word order in the absence of a sentence boundary pause.
a. Was glaubst du, mit wem Maria gesprochen hat? what believe you with whom Maria talked has
b. *Was glaubst du, mit wem hat Maria gesprochen? what believe you with whom has Maria talked 'Who don't you think that Maria talked to?'

A second kind of root clause behaviour of $w$ h-slifted clauses is the fact that they cannot be embedded questions. (28) shows that long wh-movement is fine in embedded questions, but wh-slifting is poor, with or without subject-aux inversion in the main clause.

a. I wonder how old you think she is.

b. *I wonder how old is she (do) you think.

German scope-marking constructions, on the other hand, are fine in embedded questions.

(29) Ich weiss nicht was er denkt welches Buch sie gelesen hat.

I know not what he thinks which book she read has.

'I don't know which book he thinks she read.'

(Beck and Berman, 2000:25)

\subsection{Person restrictions}

An additional way in which English questions like (1) and (2) differ from German/Hindi scope marking constructions and Basque-type clausal pied piping sentences is in terms of person restrictions on the main clause subject. (Lahiri, 2002:506) notes that subjects other than pronominal you are degraded in $w h$-slifting questions, as illustrated in (30) and (31).

?? Who did John see does Bill believe?

(Lahiri, 2002:506)

(31) ?? How old is she do the judges suppose?

In section 3 below, we show that this restriction is not absolute: (30) and (31) improve somewhat in discourse contexts where it is presupposed that the main clause subject has a belief about the issue raised in the slifted clause. What is important for present purposes, however, is that neither scope marking constructions nor Basque clausal pied piping constructions are restricted in this way. (32) and (33) are examples 
from the literature showing that scope marking constructions in Hindi and German, respectively, are fine with non-second person subjects out of the blue.

rameS kyaa soctaa hai ki raam-ne kitnii kitabeN paRhiiN?

Rames what thinks that Ram-ERG how many books read-PST

'How many books does Rames think that Ram read?'

(Lahiri, 2002:520)

(33) Was glaubt Karl mit wem Maria gesprochen hat?

What thinks Karl with whom Maria spoken has

'Who does Karl think that Maria has spoken to?'

(Dayal, 2000:p. 158)

Similarly, clausal pied-piping is fine out of the blue with non-second person subjects in the higher clause.

[Nor-k irabazi-ko duela] esan du Jon-ek?

Who-erg win-fut aux say aux Jon-erg.

'Who does Jon think will win?'

We return to these person restrictions below. To summarize, in this section we have compared questions like (1) and (2) to scope marking constructions in several languages and embedded clause pied-piping of the Basque type. We have shown that neither a Basque-type complement clause pied piping approach, nor indirect dependency approaches to scope marking constructions (as suggested by Kayne 1998) are empirically adequate for expressing key properties of these constructions. In the next section, we propose that interrogative slifting constructions are more usefully analyzed as a close cousin of declarative slifting sentences.

\section{The relationship between $w h$ - slifting and declarative slifting}

In this section, we compare sentences like (1) and (2) to declarative slifting sentences as in (35) - (37), first described by Ross (1973).

(35) Max is a Martian, I believe.

(Ross, 1973:131)

(36) There are 11 planets, Max thinks

(Ross, 1973:138)

(37) There was something funny about Venus, it seems to me.

(Ross, 1973:138)

Ross includes yes/no slifting questions in his analysis in discussing examples like (38). 
In the discussion below, we show that yes/no interrogative slifts behave similarly to the wh-slifting questions in (1) and (2). We show also that while interrogative slifting constructions are akin to declarative slifting sentences like (35)-(37), the former are more restricted in several ways including especially the class of main clause predicates that allow for slifting. A focus of much of the literature on declarative slifting has been the relationship between the main clause and the slift. In particular, two main approaches to this issue have been proposed in the literature. Ross's (1973) analysis was that slifting sentences were transformationally derived from sentences where the slift is generated as the complement of the main clause - the clause on the right in (35)-(37). Specifically, the rule deletes the complementizer that and adjoins the lower clause to the top node of the lower as in (39) which is adapted from Ross $(1973: 134))$.

$$
\text { [So [s2 Max is a Martian] [s1 I feel]] }
$$

Working in more contemporary frameworks, Reinhart (1983), Corver and Thiersch (2001) and Rooryck (2001a,b) recast this idea in terms of movement of the slift as in (41). In the following discussion we will refer to this approach as the clausal movement approach.

\section{Clausal movement approach}

[CP [Max is a Martian] [ C [IP I feel <Max is a Martian>.]]]

A second approach, proposed first by Jackendoff (1972), is that the two clauses are base generated in the order in which they appear in (35) - (37) where the clause on the right is a parenthetical adjunct to the main assertion to its left. A variant of this approach by Collins and Branigan (1997) and Corver and Thiersch (2001), assumes that the slifted clause (or part thereof) is anaphorically linked to an operator, first merged as the complement of the matrix predicate. We will shortly see reason for thinking that this analysis, if correct, involves movement of the operator to the left periphery of the matrix clause, as in (41). We refer to this approach henceforth as the null operator approach.

$$
\begin{aligned}
& \text { Null operator approach } \\
& {[\mathrm{CP} \text { Max is a Martian }]_{i}\left[\mathrm{CP}_{\mathrm{Cp}}\left[\mathrm{TP} \text { I feel }<\mathrm{Op}_{i}>\right]\right]}
\end{aligned}
$$

We consider virtues of these two approaches to wh-slifting as we compare declarative slifting and wh-slifting in the discussion below. We begin by discussing shared 
properties of these two constructions.

\subsection{Shared properties of declarative slifting and wh-slifting}

\subsubsection{Island effects.}

One kind of evidence cited by Ross for raising of the slifted clause is that it gives rise to complex DP-island and coordinate-island violations, as in (42) and (43). (For the moment, we remain agnostic about whether the complement of the slifting predicate is occupied by a copy of the slifted clause or an operator, and represent this position with an underscore.)

Max has a tuba, I believe (*your claim) that Pete pointed out

(Ross, 1973:151)

* Max has a tuba, Ted is reading a book and will find out

(Ross, 1973:151)

Parallel examples are difficult to construct for wh-slifting, owing to additional restrictions on slifting predicates, which we discuss shortly. Nevertheless, most speakers find a difference between (44) and (45), suggesting a wh-island effect for wh-slifting sentences.

?How old is she, do you think she said _ _ ${ }^{4}$

*How old is she, do you wonder whether she said__?

Assuming that subjacency is a condition on movement, the facts in (42)-(45) suggest movement of some island-sensitive element out of the relevant islands in these examples. These facts, however, shed no light on what this element might be on the two approaches discussed above. On Ross' movement analysis, it is the slift itself, which moves out of the islands in (42)-(45). On approaches that assume a null operator mediating the relationship between the slift and the matrix clause, it is presumably raising of the null operator that gives rise to these effects.

\subsubsection{Backwards binding.}

The shared properties of declarative and wh-slifting discussed so far have not helped in adjudicating between the clausal movement and null operator approaches

\footnotetext{
${ }^{4}$ Interrogative slifting predicates with an embedded clause, such as (44), are difficult for many speakers for reasons to be made clear shortly, but can be improved with appropriate discourse scaffolding. Consider (44) in the following context. The addressee of (44) has just gone on a blind date and is now home reporting to his/her roommate how the date went, but doesn't remember all the details. The roommate interrupts the report to ask (44).
} 
outlined above. Evidence from two kinds of anaphoric dependencies, however, is more revealing, and disfavours a clausal movement approach. The first set of facts comes from anaphor and variable binding. As noted by several authors, backwards variable binding is generally poor in declarative sentences such as (46) (Corver and Thiersch, 2001; Grimshaw, 2010). ${ }^{5}$

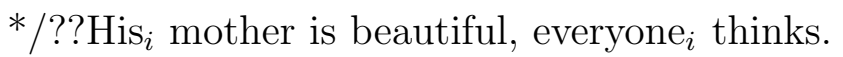

As shown in (47), backwards binding with interrogative slifting is similarly bad.

*How old is his ${ }_{i}$ mother, does everyone ${ }_{i}$ think?

These facts contrast with the much-studied availability of backwards binding in wh-questions and topicalizations.

(48) Which picture of himself does everyone $_{i}$ like best.

(49) Kiss her $_{i}$ mother, every $\operatorname{girl}_{i}$ will gladly do.

Similarly, backwards anaphor binding is generally unavailable for most speakers in wh-slifting examples, though some speakers accept it marginally.

*/? Which picture of himself ${ }_{i}$ was downloaded most did he $\mathrm{e}_{i}$ think?

The unavailability of backwards binding in these examples, therefore suggests no possibility of reconstruction of the slifted clause to a first-merged position below main clause. ${ }^{6}$ This is an awkward fact for the clausal movement approach given the availability of variable/anaphor binding under reconstruction in other A'-movement contexts.

\subsubsection{Tense agreement.}

Similarly problematic facts for the clausal movement approach come from sequence of tense dependencies as noted by Reinhart (1983). ${ }^{7}$

\footnotetext{
${ }^{5}$ Reinhart (1983) and Corver and Thiersch (2001) in fact propose that binding is sensitive to the interpretation of the slifting sentence. Specifically, Reinhart distinguishes between a "subject oriented" (free indirect discourse) interpretation, and a "speaker oriented" parenthetical interpretation. "Subject oriented" interpretations will not be relevant to the interrogative slifting constructions focussed on here and we set discussion of these facts aside here.

${ }^{6}$ Compare the absence of a Principle C effect in (22), which also shows that the slift does not reconstruct, i.e. has not undergone movement.

${ }^{7}$ Sequence of tense facts were discussed originally by Ross (1973), who invoked these facts in support of a transformational account. Specifically, Ross notes that when some main clause predicates
} 
Consider the dialogues in (51) and (52), which we use to stifle a free indirect discourse reading. In (51b), the past modal would in the embedded clause is fine on an interpretation where the coming by event is located after the utterance time. In contrast, would in the slifted clause in the counterpart wh-slifting example in (52) cannot have this same interpretation, plausibly because it cannot establish the requisite dependency with a matrix T providing the evaluation point (Giorgi, 2009).

(51) a. A: Ruth said she would come by at 5, and it's 5.40 now.

b. B: She said (she'd/she'll) come at 6 .

(52) a. A: Ruth said she would come by at 5, and it's 5.40 now.

b. B: She'll/?She'd come by at 6 , she said.

Note, in contrast, that backwards tense agreement is fine in clausal topicalization sentences.

(53) That John would come by later, they assured us.

(54) When John would come by exactly, they didn't say.

Tense agreement in wh-slifting sentences is similarly constrained. The long whmovement context in (55) can have an interpretation where the coming by event is after the utterance time, but this same interpretation is out in the slifting example in (56).

(55) When did you say you would come by?

(56) *[When would you come by], did you say?

Absence of tense agreement is therefore mysterious if the slifted clause is first merged as a complement of the slifting predicate as in the clausal movement approach.

is in the past tense, the slifted clause must also be in the past, as in Ross' example in (i).

(i) There was/*is something funny about Venus, it seemed to me. (Ross, 1973:p 139)

As we discuss below, many predicates, like seem that allow for declarative slifting do not allow wh-slifting. Our focus in this paper is not declarative slifing and we set aside the nature of the tense facts in Ross' example. 


\subsection{Differences between declarative slifting and interrogative slifting}

The discussion so far has described several ways that sentences like (1) and (2) are unlike wh-scope marking constructions and Basque-type clausal pied-piping constructions, and suggested ways that such sentences are akin to declarative slifting sentences. In this section, we discuss several differences between declarative slifting and interrogative slifting, which suggest that the two are partially different phenomena.

\subsubsection{Restrictions on slifting predicates.}

A first difference between interrogative and declarative slifting not noted in any of the literature as far as we are aware is that the class of predicates that allows for interrogative slifting is much more restricted than those that allow for declarative slifting. Hooper's (1975) extensive discussion of root and non-root assertion types lists 66 predicates that allow for slifting. These include verbs of saying and belief, be obvious/likely/clear, factives, raising verbs like seem/appear as well as manner of speaking verbs. A sample of these is shown in (57).

\section{Some predicates that allow declarative slifting}

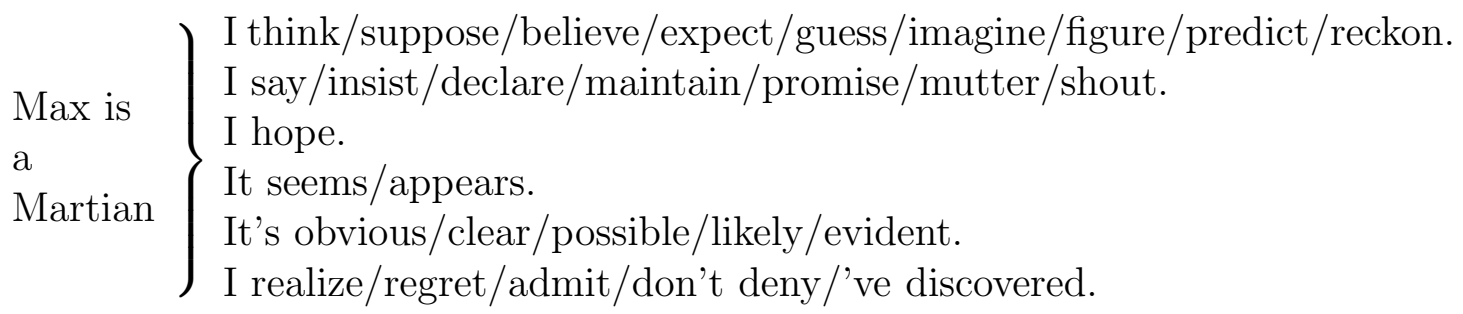

The set that allows for interrogative slifting is much more restricted as shown in (58). This set includes say and verbs of belief, but excludes factives, manner of speaking verbs and predicates like be obvious/clear/likely/probable. 


\section{some predicates that do and don't allow interrogative slifting}

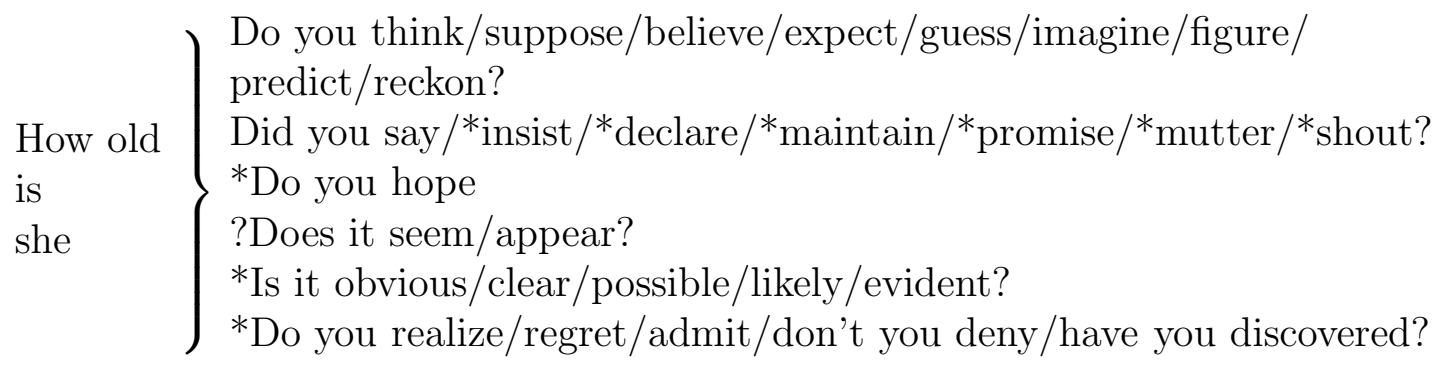

An initially appealing approach to the difference in the behaviour of the predicates in (57) and (58) is to relate it to constraints on long wh-movement. If wh-slifting constructions are derived in a way similar to long wh-movement constructions, then we might expect representational or interpretive constraints accounting for island effects generally to apply in wh-slifting contexts as well. Indeed, as shown in (59)(61), predicates like be obvious/clear/possible/likely as well as the factive and manner of speaking verbs are all degraded in long wh-movement sentences akin to (58).

$$
\begin{aligned}
& \text { How old is it *obvious/*clear/?likely/?possible she is }<\text { how old }>\text { ? } \\
& \text { How old do you } * \text { realize } / * \text { admit/*regret she is }<\text { how old }>\text { ? } \\
& \text { How old did you } * \text { mutter } / * \text { shout she is }<\text { how old }>\text { ? }
\end{aligned}
$$

Nevertheless, such an account leaves unexplained the fact that verbs like hope, maintain, promise, which are all transparent to long wh-extraction are poor with wh-slifting.

(62) How old do you hope/maintain/promise she is $<$ how old $>$ ?

The difference in the behaviour of the predicates in (57) and (58) appears rather to be related to evidential meaning, as suggested by work on slifting in English and slifting and embedded V2 in German (Hooper, 1975; Rooryck, 2001a,b; Simons, 2007; Truckenbrodt, 2006; Davis et al., 2007; Scheffler, 2009). In particular, predicates that allow for interrogative slifting appear to fall into one of two main classes. The largest class, in the top row in (58), are verbs like think, suppose etc. that describe a salient participant's beliefs about the proposition described in the slift. In addition, the verb say participates (with both an indirect speech and reported belief interpretation - Would you say...?), but not manner of speaking verbs. Scheffler (2009) suggests that many predicates that allow for embedded V2 and slifting 
in German have the function of hedging the epistemic commitment of the speaker (for declarative slifting) or hearer (in the case of interrogative slifting) to the truth of proposition in slifted clause. That is, an interrogative slifting construction with think/believe/guess invites the hearer to assume a lower evidentiary threshold in answering the question in the slifted clause, in a way perhaps akin to the adoption of a higher alpha-value in inferential statistics. Factive predicates like know, and those like hope or promise, which do not invite the hearer to lower his or her evidentiary criterial value in this way are not felicitous as wh-slifting predicates. (See also Davis et al. 2007 and Lassiter 2011 for a discussion of the probabilistic pragmatics of evidentials and modality more generally.) Something more, however, is needed to explain the unavailability of $w$ h-slifting with predicates like be likely/possible/probable, and seem/appear, which have a similar evidential contribution to the epistemic verbs in (58), but are marginal or downright bad with interrogative slifting. The difference between these classes of predicates and the belief/say verbs in (58) is that the former are incomplete as evidentials in that they do not explicitly describe sources of evidence - a relevant participant's beliefs or speech-for the proposition described in the slift (Rooryck, 2001a,b). Similarly, note that interrogative slifting predicates with seem/appear are acceptable for most speakers with an experiencer PP, as in (63) and (64), but generally marginal otherwise.

(63) How likely is Mexico to win the World Cup, does it seem ?(to you)?

(64) Is Marta the world's best footballer, does it appear ?(to you)?

The incompatibility of negation in the main clause with interrogative slifting might be explained in similar terms. That is, we suggest that questions like (19b), repeated here, are bad because the negated belief/saying predicates cannot easily be epistemic/evidential hedges in the way just described (Scheffler, 2009).

a. Who don't you think/do you not think [ <who $>$ will come ]?

b. *[ Who will come ] don't you think/do you not think?

To summarize, interrogative slifting clauses are strictly limited to evidential predicates of a certain sort, namely those that describe sources of belief or indirect speech relevant to the evidential evaluation of the question in the slift. Declarative slifting, which co-occurs with factives and a wide range of verbs of saying, are not constrained in this way. 


\subsubsection{Defocussing}

A second way in which interrogative slifting constructions are more restricted than declarative slifting sentences is that in the former, but not the latter, the parenthetical main clause must be defocussed, that is, refer to discourse-old information. (65) and (66) show that in interrogative slifting constructions, material in the main clause can never be stressed unlike counterpart long wh-extractions. ${ }^{8}$

How old is she, did you/*YOU say/*SAY.

How old did you/YOU say/SAY she is.

Declarative slifting main clauses, on the other hand, freely permit stressed material.

She was with Bill, HENRY thinks at least.

In addition, speakers typically prefer pronouns to full DPs as the subject of the slifted clause. As discussed earlier, (Lahiri, 2002:506) reported that subjects other than pronominal you are degraded in interrogative slifting constructions, as illustrated in the contrast between (30), repeated here, and (68).

(30) ??Who did John see does Bill believe? (Lahiri, 2002:506)

(68) Who did John see do you believe?

We return to the person effect that Lahiri notes shortly. For the moment, let us focus on two facts suggesting that the contrast between (30) and (68) is partly attributable to the fact that the parenthetical main clause material must be discourseold. First, (30) is immediately more natural for most speakers if the main clause subject is a third person pronoun rather than Bill.

?Who did $\mathrm{John}_{i}$ see does he ${ }_{k}$ believe?

Second, note that Lahiri's example in (30) becomes much more natural in a context in which it is presupposed that Bill has a belief about a set of alleged events. In the

\footnotetext{
${ }^{8}$ Probably relevant here is the fact that the main clause in both declarative and $w h$-slifting sentences typically co-occurs with an intonational downstep:

(i) Who did John see [ $\downarrow$ do you believe]?

(ii) Max is a Martian [ $\downarrow$ I believe].

We do not attempt here to spell out the syntax-to-prosody mapping of such constructions. See Dehé (2009) for discussion.
} 
context of A's utterance in (70), for example, a question like (30), B's response, is fine for many speakers. ${ }^{9}$

(70) A: Bill thinks that John was present in the hotel at the time of the murder. According to Bill, John was downstairs in the lobby reading a newspaper and actually saw the murderer come in through the front door.

B: And who did John see, does Bill believe?

The interaction of this givenness constraint and its restriction to evidential interpretations has the consequence that interrogative slifting clauses are restricted in content to discourse-given descriptions of the hearer's or a third person's epistemic commitment to the proposition in the slift. For this reason, in the absence of some rescuing context, interrogative slifting constructions are poor with adverbials and other main clause material modifying the epistemic predicate as shown in (71)-(73). (See also footnote 4.)

(71) Will Mexico score first, do you *often/*occasionally/*secretly believe?

(72) How old is she, do you *often/*occasionally/*secretly think?

*How old is she, are you sorry to say?

Declarative slifting main clauses, on the other hand, are fine with modifiers of this sort:

Jules is a bit boring, I often/occasionally/secretly think.

Omar is coming, I'm deeply sorry to say.

\subsubsection{Person restrictions.}

Plausibly related to these constraints are person restrictions on the subject/experiencer of the main clause. Hooper (1975) and Rooryck (2001a,b) note that declarative slifting sentences are often most natural in contexts where the subject of the main clause

\footnotetext{
${ }^{9} \mathrm{~A}$ reviewer asks about the presupposed status of the predicate of the main clause. The contrast in (65) indicates precisely that as a presupposed element the predicate cannot be the target of corrective focus. Furthermore, one way to address the relevant presupposition is by using so-called "presupposition suspenders" (Horn, 1972; Abbott, 2006) (i):

(i) How old is she, did she say, if she ever actually did.

If Horn (1972) and Abbott (2006) are correct, this type of if-clauses serve to temporarily suspend the presupposition associated with an element.
} 
is first person. For example, be afraid, with an epistemic meaning, is degraded as a slifting predicate with second or third person subjects, but fine with first person.

$$
\text { Omar is coming, I'm/?you're/?Mary's afraid. }
$$

For declarative slifting constructions, this effect is fairly weak in that many other slifting verbs combine naturally with non-first-person subjects.

Omar is coming, John believes/they've discovered.

Interrogative slifting constructions on the other hand are more restricted, with the crucial additional difference that, out of the blue, it is second person arguments that are typically preferred (Ross, 1970; Lahiri, 2002). Note, as illustrated in Ross' example below, this person restriction applies to the experiencer argument - that is to the "evidential source" - rather than to the subject, for predicates where these are different.

$$
\text { Are you drunk, does it seem (to you/?me)? }
$$

(Ross 1973:49)

Nevertheless, as illustrated in (69) and (70) above, third person evidence sources are also available, provided there is appropriate discourse scaffolding. The reason why a first person main clause subject is usually infelicitous is that we do not often ask other people questions about our own epistemic commitments. Consider, however, a context in which a family is in a queue to buy tickets at the cinema, debating whether to ask for children's price for a daughter, who is in fact too old for this price. In such a context, (79) below, with we or $I$ as the matrix subject is perfect.

$$
\text { How old is Amy, should we/I say? }
$$

The sensitivity of these person restrictions to clausal force- first person arguments are somewhat preferred in declarative slifting and second person subjects are favoured in interrogative slifting - is plausibly related to the givenness restriction discussed above together with pragmatic properties of the embedded clause. As Simons (2007) notes, declarative slifting sentences like (35)-(37) have the property that the slifted clause constitutes the main point of the utterance (MPU). Unlike in other kinds of embeddings, the matrix clause is not the main point of the utterance but rather typically has an evidential/quotative function. ${ }^{10}$ In particular, Simons likens such

\footnotetext{
${ }^{10}$ Simons' approach is very close in spirit to that of Hooper and Thompson (1973) and Hooper (1975) who take the slifted clause to be the assertion. However, Simons rejects the notion of assertion in such cases since assertion involves a commitment to the truth of a proposition and
} 
slifting examples to sentences like B's answers in (80b)-(80d), which can be felicitous responses to A's question. That is, in these question-answer pairs, like in the slifting examples in (35)-(37), the embedded clause provides the main point of B's response and the main clause is interpreted as an evidential. Other predicates including most factives cannot felicitously take main point embedded complements as illustrated in the examples in (80e) in this dialogue (adapted from Simons 2007).

A: Who was Louise with last night?

B:

a. She was with Bill.

b. Henry thinks/believes/hopes that she was with Bill.

c. Henry said/suggested/promised that she was with Bill.

d. It's clear/obvious/true that she was with Bill.

e. \#Henry knows/regrets/found out that she was with Bill.

Interrogative slifting constructions are parallel to the declarative slifting examples in (35)-(37) in that the slifted clause contains the main point of the utterance - the main information request (MIR) in an interrogative context - while the main clause has an evidential/quotative interpretation. (We provide a more formal characterization of MIR in section 4.) We take these facts to underlie the relationship between interrogative/declarative force and the subject person restrictions described above. In declarative slifting sentences, the main point of the utterance is the proposition in the slifted clause, and the speaker's beliefs about that proposition are presupposed by the act of making this main point (or "assertion" in Hooper and Thompson's (1973) and Hooper's (1975) analyses). It is for this reason that first person arguments are somewhat more natural than other persons as main clause subjects in declarative slifting sentences, that is, because the speaker's beliefs are made contextually relevant by the declarative speech act. Similarly, in interrogative slifting contexts, the main information request in the slifted clause implicitly asks for the hearer's beliefs about the set of propositions presupposed by the act of asking the question to the hearer. Consequently, second person subjects are particularly natural out of the blue in interrogative slifting sentences, since the hearer's beliefs about the set of propositions introduced by the question in the slift is presupposed. As we have seen, for other subject persons to be presupposed as an evidential source, additional contextual support is required. The fact that the person effect is stronger in interrogative

the function of the main clause predicate in many such cases is to weaken the speaker's epistemic commitment to the proposition in the slifted clause as discussed above. 
slifting constructions than in declarative slifting is a consequence of the fact that the givenness requirement is stricter in the latter as noted earlier. We attempt to formalize these restrictions in section 4 .

\subsubsection{Word order.}

A final key difference between declarative and interrogative slifting concerns word order. One argument against the transformation/movement analysis, which is discussed by Ross (1973) and recognized as a problem, is that the parenthetical main clause can appear inside the slifted clause as a parenthetical, by the look of it.

The children (she said) will (she said) come back (she said) in two days time (she said).

Importantly, for our purposes, $w h$-slifting is more restricted in this regard. The only well-formed alternative to final position of the main clause is immediately following the initial wh-phrase, as in (82). We will come back to the question of how this "split-parenthetical" word order can be derived in section 4 .

When on earth (do you think) will (??do you think) the children (??do you think) come back (do you think)?

To summarize, in this section, we have shown that interrogative slifting constructions are close cousins of declarative slifting sentences, but are more restricted in three main ways: first, the main clause in the former but not the latter must have an evidential interpretation; second, interrogative main clause material must be discourse given; and third, interrogative slifting is much less permissive in terms of parenthetical word orders where the main clause appears interposed among slifted clause material. In the following section we develop an analysis of these facts and other properties of interrogative slifting constructions introduced in section 2.

\section{An evidential structure for interrogative slifting constructions}

Our analysis of the properties of interrogative slifting sentences described in sections 2 and 3 will have two main components: first an account of root clause properties of the slifted clause, and second a proposal that the slifted clause and the parenthetical main clause are merged together in a phrase headed by a null evidential morpheme. We discuss these two proposals in turn below.

\subsection{Root clause properties}

There is a general agreement in the literature that Root status correlates with illocutionary force in something like the original sense going back to Austin (1962). 
That is, root clauses assert (in the case of declaratives) the truth of the proposition they contain, and thus entail a commitment to the truth of the sentence by the speaker. A number of authors have also suggested that illocutionary force ought to be encoded syntactically as a Force head in the left periphery of the clause (Hooper and Thompson, 1973; Vikner, 1995; Haegeman, 2004, 2006; Zanuttini and Portner, 2003; Heycock, 2006; Julien, 2008; Sheehan and Hinzen, 2011). The term Force was used by Chomsky (1995) to denote mostly what Cheng (1997) called clause type. Rizzi (1997) adopts Chomsky's term and uses it in the same way. So ForceP, as used by Rizzi, is not directly connected to illocutionary force but at the same time it is not entirely divorced from it. We can say that apart from clause type (declarative, interrogative etc...), ForceP also indirectly encodes the illocutionary potential of a clause. ${ }^{11}$ In other words, in the standard case, a clause whose Force head is specified as, say, declarative, has the illocutionary potential of an assertion whereas interrogative force will correlate with the illocutionary potential of a question. Crucially, however, a force specification alone is not sufficient to confer root status to a clause. For this, something more is needed. In the spirit of representing illocutionary force syntactically, we propose that a clause with force $\mathrm{F}$ acquires illocutionary force/becomes a speech act when a clause-typing is in a relationship with a speech act-related head. For clarity, let us call the latter the Speech Act Operator and propose that this operator is endowed with a $u$ Force feature which must be valued by an appropriate Force feature in its domain ensuring compatibility between clause type and speech act. In the general case, we will have something like the following:

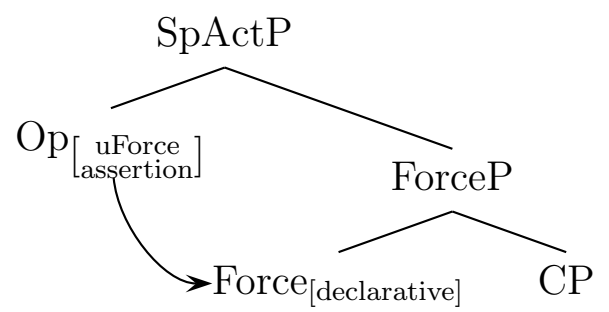

There are various ways to achieve the relevant relationship. We propose that the presence of a Force morpheme atop the slifted clause in interrogative slifting constructions explains certain root-clause behaviour of these clauses discussed in sections 2 and 3. First, we assume that an interrogative force head, Force-Int, is responsible for obligatory subject-aux inversion in English in triggering T-to-C movement. More precisely, we assume that Force-Q selects a $\mathrm{C}$ with an unvalued $\mathrm{V}$-feature, trigger-

\footnotetext{
${ }^{11}$ We use the term Illocutionary Potential in much the same way that Wechsler (1991) does.
} 
ing verbal T-to-C movement. We assume, furthermore, that wh-questions are made up of a proposition with a variable bound by a wh-operator, where the operatorvariable relation is derived by wh-movement. Assuming a Chomskyan feature theory (Chomsky, 1995, 2001), we assume wh-movement is triggered by a $[u \mathrm{WH}]$ feature in the C-domain. This much is true of main and embedded clause wh-questions alike. Main clause questions (direct questions) can function as such because the Speech Act Operator's [ $u$ Force] feature is valued directly by the Force-Int feature of the Force Head. On these assumptions, slifted wh-questions in sentences like (1) and (2) will be derived as in (84).

[Force-Int [ $\mathrm{C}_{[\mathrm{uWH}, \mathrm{uv}]}[\mathrm{TP}$ John $\mathrm{T}[\mathrm{vP}$ go where $\left.\left.]]\right]\right] \rightarrow$

[Force-Int [where[ did $+\mathrm{T}+\mathrm{C}_{\text {[uwh,uv }}[T P$ John did $+\mathrm{T}[\mathrm{VP}$ go $\left.]]\right]$

The fact that wh-slifting questions cannot be embedded questions, as illustrated in (28) repeated here is similarly attributable to the fact that predicates selecting embedded questions wonder, know, etc. require that their complements lack an interrogative force feature.

a. I wonder how old you think she

b. *I wonder how old is she do you think.

In this way, the assumption of a Force head in the slifted clause helps express the root clause properties of slifts introduced in sections 2 and 3. Something further, however, is needed to account for the pragmatic relationship between the slift and the parenthetical main clause. On the standard view, the pragmatic contribution of interrogative force - here encoded by Force-Int - is to make the expression a request for information. Note however, the main clause, too, has subject-aux inversion and therefore has a Force feature. So the interrogative slifting construction conveys two questions, two requests for information. What is the relation between them? We have previously proposed, by analogy with Simons's (2007) account of declarative slifting, that the slift is the main request for information (MIR) while the main clause is 'parenthetical', discourse-given, with an evidential/quotative function. Simons (2007) defines the MPU as follows:

(85) The main point of utterance $\mathrm{U}$ of a declarative sentence $\mathrm{S}$ is the proposition p communicated by $\mathrm{U}$ which renders $\mathrm{U}$ relevant.

As discussed earlier, Simons uses question-answer pairs to diagnose main point content. We will define the MIR in a way analogous to the MPU. The following working definition is sufficient for our purposes: 
The main information request of an utterance $\mathrm{U}$ of an interrogative sentence $\mathrm{S}$ is the question $\mathrm{Q}$ denoted by $\mathrm{S}$ in Context $\mathrm{C} .{ }^{12}$

Following Hamblin (1973) and subsequent work, we take the denotation of a question to be the set of alternative propositions that may be answers to the question. ${ }^{13}$ The pragmatic function of the question is to request that the hearer identify the alternative proposition that is the relevant true answer in the context. Just as in the case of the MPU, where the question diagnoses the MPU content in the answer, in the case of the MIR, the answer diagnoses MIR content in the question. Thus, for the interrogative slifting example in (87), yes will be a felicitous answer if did she say...? is the MIR and 45 is felicitous if How old is she? is the MIR.

How old is she, did she say?

Note that a yes/no answer is not a felicitous response to (87) unless a there is a heavy intonational break between the two clauses, a partially distinct phenomenon that we do not consider here. ${ }^{14}$ Without such a break, only an answer responding to How old is she? will be felicitous, suggesting that this must be the MIR, and that the say-clause cannot be construed as the MIR.

The question, then, is how to account for the obligatory MIR-hood of the slift vis-à-vis the parenthetical clause. In the following section, we consider this problem further in light of the external syntax of slifted clause and in particular the syntactic relationship between the slift and the parenthetical main clause.

\subsection{The relationship between the slift and parenthetical main clause}

We begin by considering the evidential interpretation of the parenthetical clause. The most explicit syntactic approach to the evidential meaning of declarative slifting sentences is by Rooryck (2001a,b), who takes the relationship between the two clauses

\footnotetext{
${ }^{12}$ For clarity, we use the terminology of Groenendijk and Stokhof (1984), where the term "interrogative" is used to describe a class of syntactic forms and the term "question" their semantic content.

${ }^{13}$ For our purposes it is immaterial whether the set of alternatives includes all answers (as suggested by Hamblin (1973) or, as Karttunen (1977) suggested, only its true answers.

14 Wh-slifting constructions are pragmatically very similar to the interrogative construction in (i) not uncommon in colloquial English as an alternative to interrogative slifting.

(i) What do you think-how old is she?

There are important differences, though, between the two constructions, including the fact that the dual-question construction has a clear intonational break, the say-sentence need not be defocussed, and it is less sensitive to person restrictions. We conclude therefore that such utterances constitute a partially independent phenomenon and set them aside here.
} 
to be mediated by an evidential head, $\operatorname{Mood}_{\text {Evidential }} \mathrm{P}$ (Cinque, 1999). Specifically, Rooryck proposes that the slift is merged as the complement of the main clause, and then raises to the specifier of the evidential projection. The evidential interpretation of some main clause verbs is a consequence of their raising to the $\operatorname{Mood}_{\text {Evidential }}$ head. This movement is covert in most declarative slifting contexts where the subject precedes the verb but overt in quotative inversion contexts. We illustrate these two possibilities in (88)-(89) (adapted from Rooryck 2001a).

$$
\begin{aligned}
& \text { [MoodEvidP [CP Jules is back] MoodEvid' } \\
& \text { [MoodEvidP [CP Jules is back] MoodEvid'said [TP she [ } \mathrm{T}^{\prime} \text { [VP }
\end{aligned}
$$

For the purposes of modeling the properties of interrogative slifting sentences focused on here, Rooryck's approach has three main disadvantages. First, this account is not particularly well suited to expressing the fact that the evidential and givenness restrictions in interrogative slifting constructions are properties of the parenthetical main clause as a whole and not just the verb. Second, as noted in section 3, the absence of backwards variable binding and sequence of tense is mysterious from the perspective of clausal movement approaches like that illustrated in (88) and (89), where the slifted clause is first merged as a complement of the main clause. Third, it does not allow for a particularly natural way of expressing split parenthetical word orders. To derive the order in (90) on this approach, some further assumptions appear necessary, such as lowering of is back or raising of the main clause followed by sub-extraction of Jules. None of the solutions available appear trivial.

Jules, she said, is back.

We follow Rooryck (2001a,b) in taking the relationship between the parenthetical main clause and the slift to be mediated by a silent evidential morpheme. We propose, though, that these two clauses are initially merged together in a structural relationship opposite that proposed by Rooryck: the parenthetical main clause is merged as the specifier of the evidential head responsible for the evidential interpretation of this constituent; the slift is merged as the complement of this head. We propose (along with Kayne 1998:174 and Lahiri (2002)) that a null operator is merged as the complement of the main clause predicate and undergoes movement, akin to wh-movement, to the left periphery of that clause. In the spirit of Collins and Branigan's (1997) and Suñer's (2007) approaches to direct quotes, we propose that this null operator is coindexed with the slifted clause. As suggested in section 3 , we propose that it is the null operator movement that is responsible for the island effects inside the main clause. We illustrate this structure in (91). We will continue 
calling it 'the main clause' even though it is now reduced to a specifier argument of an evidential head.

$$
\begin{aligned}
& \left.\left[\text { EvidP }_{\mathrm{CP}-\mathrm{Q}} \mathrm{Op}_{[\mathrm{Q}] i} \text { Main clause } \mathrm{Op}_{[\mathrm{Q}]}\right]\right]_{[\text {Evid Evid }[\mathrm{CP}-\mathrm{Q}} \text { Force-Q } \mathrm{Q}_{i} \ldots \text { Slifted } \\
& \text { Clause]]] }
\end{aligned}
$$

Our proposal for slifting movement departs from two observations about information structural constraints on interrogative slifting constructions made in section 3. First, we noted that in interrogative slifting constructions, the main parenthetical clause must be very strictly discourse-given, unlike in declarative slifting constructions. Second, we noted that word order possibilities in 'split parenthetical' sentences are more constrained in interrogative slifting constructions than in declaratives. As we noted in section 3, declarative slifting constructions are relatively free in terms of the position in which the parenthetical main clause may be interposed in the slift. We illustrate this in (92), which presents in a different format the data in (81), above. The parenthetical main clause appears in bold.

(92) a. The children, she said, will come back in two days time.

b. The children will, she said, come back in two days time.

c. The children will come back, she said, in two days time.

d. The children will come back in two days time, she said.

The different word orders illustrated in (92), however, have different focus properties. For example, as an answer to a question focussing the entire embedded clause, What did Ann say? the most natural word order, of those shown in (92) is (92d). Similarly, (92b) is most natural with a verum focus interpretation, and stress on will. As an answer to a question focussing the subject of the slifted clause, Who did Ann say will come back in two days time, main sentence stress falls on the children and the most natural word orders are (92a), with the parenthetical main clause interposed to the right of the subject, and (92d); (92b), (92c) are somewhat less natural. These facts, at first glance suggest that the generalization is that the parenthetical main clause appears most naturally either to the right of the focus-bearing constituent or to the right of the slifted clause as a whole (92d). But note, however, that as an answer to a question focussing the temporal adverbial, When did Ann say the children will come back?, the most natural placements for the parenthetical main clause are either at the end of the slifted clause, (92d), or before the focused constituent, (92c). We do not attempt to offer a complete account of the focus facts in declarative slifting sentences, which would take the discussion afield. We infer from these facts, however, that declarative slifting word orders are constrained by stress/focus properties of 
the slifted clause. Similar facts are observed by Suñer (2007) in her discussion of quotative word orders in Spanish. Suñer notes that in 'split quotation' word ordersthat is, where the quotative verb interposes inside quoted material - the portion of the quote before the quotative verb tends to be stressed, while the material following the quote has a flatter intonational contour. Suñer proposes that in such cases, the stressed material is linked to a null operator in the specifier position of a focus head high in the main clause.

"Claro," comprendió el viejo, "les ha dicho el médico que me queda poco..." "Of course," understood the old-man, "the doctor has told them that I have little time left.

Suñer $(2007)^{15}$

In section 3, we noted that interrogative slifting constructions are more restricted than declarative slifting constructions in allowing the parenthetical main clause to appear either following the slifted clause or to the right of the wh-phrase, as in (82), repeated here.

(82) When on earth (do you think) will (??do you think) the children (??do you think) come back (do you think)?

We adapt Suñer's proposal for quotative constructions in proposing that slifting movement involves movement to a focus position above the evidential head. Specifically, we propose that the focus head probes a focus feature in the slift. In the case of $w$-slifting questions, this feature will be a property of the wh-phrase; in the case of yes/no interrogative slifting, we assume it is a property of a null operator in the left periphery of the slifted clause ('null whether', Larson 1985). By virtue of this agree relation, the slifted phrase may then raise to FocusP, assuming the presence of a movement-triggering (EPP/edge) feature. We illustrate this movement in (94).

$$
\begin{aligned}
& \left.{ }_{\text {FocusP }}\left[\mathrm{CP}-\mathrm{Q} \text { Force-Q }{ }_{i} \text { Slift }\right] \text { Focus }{ }_{\text {EvidP }}{ }_{\mathrm{CP}-\mathrm{Q}} \mathrm{Op}_{[\mathrm{Q}] i} \text { Main clause }{ }_{[\mathrm{Top}]} \mathrm{Op}[\mathrm{Q}] i\right] \\
& \text { [Evid } \text { Evid }_{[\text {Top }]} \text { Slifft]] }
\end{aligned}
$$

We assume further that this focus head selects for a complement with topic properties (Rizzi, 1997). Specifically, let us assume that the evidential head has a topic feature, which requires that the parenthetical main clause in its spec be discourse-given. Furthermore, it is plausible to assume that the movement of the slift to the focus position is indirectly at least related to its status as MIR. That is, the fact that the slift but not the parenthetical main clause bears focus features determines its

\footnotetext{
${ }^{15}$ Suñer took this example from Sampedro (1995).
} 
interpretation as MIR. (See Simons 2007:fn. 8 for likeminded remarks on declarative slifting.) Consider now, the syntactic effect of these movements. Recall first the structure in (83). Adapting it to the present case gives us (95). As is expected the $u$ Force feature of the Speech Act Operator will be valued by the closest available Force head in its domain. This will be the Force head associated with the slifted CP sitting in the specifier of the Focus phrase. This agreement between the Speech Act Operator and Force in the slift is also plausibly related to the slift's status as the MIR.

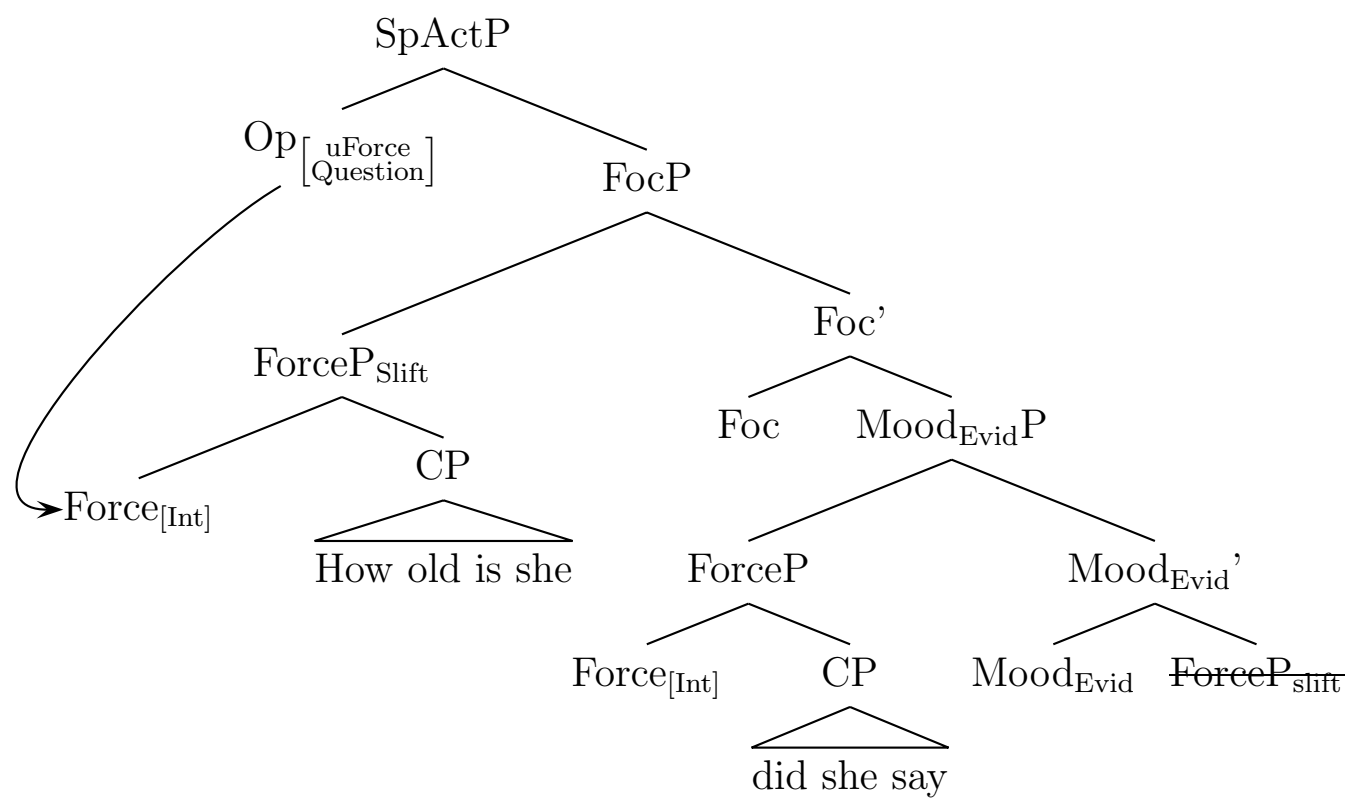

On this approach, the unavailability of backwards binding described in section 3 is a consequence of the fact that the intended antecedent in the main clause never ccommands the slifted clause, since it is first merged into the structure in the specifier of $\operatorname{Mood}_{\text {Evidential }} \mathrm{P}$. In addition, this account now lets us explain the word order patterns in (82). Specifically, let us assume that, when the focus head probes the focus feature in the slift, this feature may either pied-pipe the entire clause or just its local constituent in spec, CP. In the former case the, entire slifted clause will front, and in the latter case, just the wh-phrase will move, yielding the two word order possibilities shown in (82). Other split-parenthetical word orders are correctly excluded on this approach, since the raised constituents are not foci, and are not pied-pipable by the focus-bearing feature since they are non-constituents (without 
further assumptions of remnant movement, for example). Finally, this approach helps explain the difference between $w h$-slifting and long wh-movement constructions in terms of presupposition projection, that is, the fact that in the latter case the presuppositions of the embedded clause do not survive at the matrix level. On the present approach, this is explained as a consequence of the fact that slifted clause is not a true embedding and its presuppositions are therefore not blocked/plugged in the usual way (Karttunen, 1973).

An important question raised by this analysis is how to explain why declarative slifting sentences are less constrained in terms of evidential and old information interpretations. We do not attempt to provide a detailed account of declarative slifting constructions, whose distribution is in many respects more complex than that of interrogative slifting constructions, as shown in section 3. The present analysis, however, suggests that the parenthetical main clause in declarative slifting constructions can occupy a projection distinct from EvidP in (94), given its greater range of predicates that these constructions allow and the fact that these clauses needn't be defocussed. Similarly, the fact that different focus interpretations are available for the word orders in (92), suggests that slifting movement in declarative contexts may (sometimes) target a position other than FocusP. Future work might usefully examine focus properties of declarative slifting constructions in English more carefully.

\section{Conclusion}

This paper provides an account of "wh-slifting" constructions, which have been discussed parenthetically in some literature but nowhere in detail. We argue that these sentences are not covert scope marking constructions nor instances of embedded clause pied piping (with that-deletion) as suggested in previous literature (Ross, 1973; Horvath, 1998; Kayne, 1998; Lahiri, 2002). We show that such questions are akin to declarative slifting constructions, notwithstanding additional restrictions on evidential interpretations on the parenthetical main clause in such constructions. Drawing on Rooryck; Rooryck's (2001a; 2001b) analysis of declarative slifting and Collins and Branigan's (1997) approach to quotative constructions, we propose that the slifted clause and the so called "main clause" are merged as the complement and the specifier respectively of an evidential morpheme, where the slifted clause is coindexed with a null operator in the main clause. Our discussion has also described, but not analyzed in detail, an interaction between clausal force (interrogative vs. declarative) and evidential and information structural-restrictions on slifting constructions. Future work might usefully examine the nature of such interactions from a cross-linguistic perspective. 


\section{Acknowledgements}

We are grateful to two very insightful Lingua reviewers for comments, which have helped us revise substantially a previous draft. Thanks also to David Adger, Xabier Artiagoitia, Viviane Déprez, Arantzazu Elordieta, Urtzi Etxeberria, Ricardo Etxepare, Luigi Rizzi, Zoë Schlüter, Masaya Yoshida and audiences at Coloquio de Gramática Generativa 18, NESS (2006) and LAGB (2007) for some helpful comments on these data and these proposals. Work on this paper was supported by ESRC grant number 061-25-0033 and by a grant from the Spanish Ministerio de Ciencia E Inovación (B. Fernández, PI)(FFI2008-00240/FILO). All errors are our own.

\section{References}

Abbott, B., 2006. Where have some of the presuppositions gone?, in: Ward, B.J.B..G. (Ed.), Drawing the boundaries of meaning: Neo-Gricean studies in pragmatics and semantics in honor of Laurence R. Horn. John Benjamins, Amsterdam and Philadelphia, pp. 1-20.

Arregi, K., 2003. Clausal pied-piping. Natural Language Semantics 11, 115-143. URL: http://dx.doi.org/10.1023/A3A1024499226731, doi:10.1023/A:1024499226731.

Austin, J.L., 1962. How to Do Things With Words. Oxford University Press, Oxford.

Beck, S., 1996. Wh-constructions and transparent Logical Form. Ph.D. thesis. Universität Tübingen.

Beck, S., Berman, S., 2000. Wh-scope marking: Direct vs. indirect dependency, in: Lutz, U., Müller, G., von Stechow, A. (Eds.), Wh-scope Marking. John Benjamins, Amsterdam/Philadelphia, pp. 17-44.

Bruening, B., 2004. Two types of wh-scope marking in Passamaquoddy. Natural Language \& Linguistic Theory 22, 229-305. URL: $\quad$ http://dx.doi.org/10.1023/B3ANALA.0000015793.52445.4e, doi:10.1023/B:NALA.0000015793.52445.4e.

Cheng, L.L.S., 1997. On the typology of wh-questions. NewYork: Garland. [Also 1991 Ph.D. Dissertion, MIT. Distributed by MIT Working Papers in Linguistics].

Chomsky, N., 1995. The Minimalist Program. MIT Press, Cambridge, MA. 
Chomsky, N., 2001. Derivation by phase, in: Kenstowicz, M. (Ed.), Ken Hale. A Life in Language. MIT Press, Cambridge, MA, pp. 1-52.

Cinque, G., 1999. Adverbs and Functional Heads. A Cross-Linguistic Perspective. Oxford University Press, Oxford and New York.

Collins, C., Branigan, P., 1997. Quotative inversion. Natural Language \& Linguistic Theory 15, 1-41. URL: http://dx.doi .org/10.1023/A3A1005722729974, doi:10.1023/A:1005722729974.

Corver, N., Thiersch, C., 2001. Remarks on parentheticals, in: van Oostendorp, M., Anagnostopoulou, E. (Eds.), Progress in Grammar: Articles at the 20th Anniversary of the Comparison of Grammatical Models Group in Tilburg. Meertens Institute Electronic Publications in Linguistics, Amsterdam. URL: http://www . meertens. knaw.nl/books/progressingrammar/.

Davis, C., Potts, C., Speas, M., 2007. The pragmatic values of evidential sentences, in: Gibson, M., Friedman, T. (Eds.), Proceedings of Semantics and Linguistic Theory 17. CLC Publications, Ithaca, NY, pp. 71-88.

Dayal, V.S., 1993. Scope marking as indirect wh-dependency. Natural Language Semantics 2, 137-170. URL: http://dx.doi.org/10.1007/BF01250401, doi:10.1007/BF01250401.

Dayal, V.S., 2000. Scope marking: Cross-linguistic variation in indirect dependency, in: Lutz, U., Müller, G., von Stechow, A. (Eds.), Wh-scope Marking. John Benjamins, Amsterdam/Philadelphia, pp. 157-193.

Dehé, N., 2009. Clausal parentheticals, intonational phrasing, and prosodic theory. Journal of Linguistics 45, 569-615. URL: http://journals.cambridge.org/article_S002222670999003X, doi:10.1017/S002222670999003X.

Echeparre, R., 1997. Two types of focus in Basque, in: Agbayani, B., Tang, S. (Eds.), Proceedings of the Fifteenth West Coast Conference on Formal Linguistics, CSLI Publications, Stanford. pp. 113-127.

Giorgi, A., 2009. A grammar of Italian sequence of tense. University of Venice Working Papers in Linguistics 19, 111-156.

Grimshaw, J., 2010. Main clauses as arguments. Handout, Rutgers University. 
Groenendijk, J.A.G., Stokhof, M.J., 1984. Studies on the Semantics of Questions and the Pragmatics of Answers. Ph.D. thesis. University of Amsterdam.

Haegeman, L., 2004. Topicalization, CLLD and the left periphery, in: Shaer, B., Frey, W., Maienborn, C. (Eds.), Proceedings of the Dislocated Elements Workshop, ZAS Berlin, November 2003. ZAS, Berlin. volume 35 of ZAS Papers in Linguistics, pp. 157-191.

Haegeman, L., 2006. Conditionals, factives and the left periphery. Lingua 116, 1651-1669. URL: http://www.sciencedirect.com/science/article/pii/S002438410600101X, doi:http://dx.doi.org/10.1016/j.lingua.2005.03.014.

Hamblin, C., 1973. Questions in Montague English. Foundations of Language 10, $41-53$.

Herburger, E., 1994. A semantic difference between full and partial Wh-movement in german. Paper presented at the 1994 Annual Meeting of the Linguistic Society of America, Boston.

Heycock, C., 2006. Embedded root phenomena, in: The Blackwell Companion to Ssyntax. volume II, pp. 174-209.

Hiraiwa, K., 2005. Dimensions of Symmetry in Syntax: Agreement and clausal architecture. Ph.D. thesis. MIT.

Hooper, J., Thompson, S., 1973. On the applicability of root transformations. Linguistic Inquiry 4, 465-497.

Hooper, J.B., 1975. On assertive predicates, in: Kimball, J. (Ed.), Syntax and Semantics IV. Academic Press, New York, pp. 91-124.

Horn, L.R., 1972. Greek Grice, in: Proceedings of the Ninth Regional Meeting of the Chicago Linguistics Society, Chicago Linguistics Society, Chicago University, Chicago, Illinois. pp. 205-214.

Horvath, J., 1997. The status of wh-expletives and the partial whmovement construction of hungarian. Natural Language \& Linguistic Theory $15,509-572$. URL: http://dx.doi.org/10.1023/A3A1005842214213, doi:10.1023/A:1005842214213. 
Horvath, J., 1998. Multiple wh-phrases and the wh-scope-marker strategy in Hungarian interrogatives. Acta Linguistica Hungarica 45, 31-60.

Horvath, J., 2000. On the syntax of "Wh-scope marker" constructions: Some comparative evidence, in: Lutz, U., Müller, G., von Stechow, A. (Eds.), Wh-scope Marking. John Benjamins, Amsterdam/Philadelphia, pp. 271-316.

Horvath, J., 2006. Pied piping, in: The Blackwell Companion to Ssyntax. volume III, pp. 568-630.

Jackendoff, R., 1972. Semantic Interpretation in Generative Grammar. MIT Press, Cambridge, Massachusetts.

Julien, M., 2008. Embedded V2 in Norwegian and Swedish. Working papers in Scandinavian syntax 80, 103-161.

Karttunen, L., 1973. Presuppositions of compound sentences. Linguistic Inquiry 4, 169-193.

Karttunen, L., 1977. Syntax and semantics of questions. Linguistics \& Philosophy $1,3-44$.

Kayne, R., 1998. Overt vs. covert movement. Syntax 1, 128-191.

Lahiri, U., 2002. On the proper treatment of expletive wh in Hindi. Lingua 112, 501-540. URL: http://www.sciencedirect.com/science/article/pii/S0024384101000596, doi:http://dx.doi.org/10.1016/S0024-3841(01)00059-6.

Larson, R.K., 1985. On the syntax of disjunction scope. Natural Language and Linguistic Theory 3, 217-264.

Lassiter, D., 2011. Measurement and Modality: The scalar basis of modal semantics. Ph.D. thesis. New York University.

Legate, J.A., 2011. Warlpiri wh-scope marking. Syntax 14, 97-121. URL: http://dx.doi.org/10.1111/j.1467-9612.2011.00151.x, doi:10.1111/j.14679612.2011.00151.x.

McDaniel, D., 1989. Partial and multiple wh-movement. Natural Language \& Linguistic Theory 7, 565-604. URL: http://dx.doi.org/10.1007/BF00205158, doi:10.1007/BF00205158. 
Ortiz de Urbina, J., 1989. Parameters in the Grammar of Basque: a GB Approach to Basque Syntax. Foris, Dordrecht.

Ortiz de Urbina, J., 1993. Feature percolation and clausal pied piping, in: Hualde, J.I., Ortiz de Urbina, J. (Eds.), Generative Studies in Basque Linguistics. John Benjamins, Amsterdam/Philadelphia, pp. 189-219.

Reinhart, T., 1983. Point of view in language: The use of parentheticals, in: Rauh, G. (Ed.), Essays on Deixis. Günter Narr, Verlag, Tübingen, pp. 169-194.

Reis, M., 2002. Wh-movement and integrated parenthetical constructions, in: Zwart, C.J.W., Abraham, W. (Eds.), Studies in Comparative Germanic Syntax: Proceedings from the 15th Workshop on Comparative Germanic Syntax (Groningen, May 2627, 2000). John Benjamins, Amsterdam/Philadelhia, pp. 3-40.

Rizzi, L., 1992. Argument/adjunct asymmetries, in: Broderick, K. (Ed.), Proceedings of the North East Linguistic Society, GLSA, Amherst, Massachussetts. pp. $365-381$.

Rizzi, L., 1997. The fine structure of the left periphery, in: Haegeman, L. (Ed.), Elements of grammar. A handbook of generative syntax.. Kluwer, Dordrecht, pp. 281-337.

Rooryck, J., 2001a. Evidentiality part I. Glot International 5(4), 125-133.

Rooryck, J., 2001b. Evidentiality part II. Glot International 5(4), 161-168.

Ross, J.R., 1970. On declarative sentences, in: Jacobs, R. Rosenbaum, P. (Ed.), Readings in English Transformational Grammar. Blaisdell, Waltham, MA, pp. $222-272$.

Ross, J.R., 1973. Slifting, in: Gross, M., Halle, M., Schutzenberger, M.P. (Eds.), The Formal Analysis of Natural Languages. Mouton, The Hague. Ianua linguarum/Series maior 62, pp. 131-169.

Sampedro, J.L., 1995. La sonrisa etrusca. Alfaguara, Madrid.

Scheffler, T., 2009. Evidentiality and german attitude verbs, in: University of Pennsylvania Working Papers in Linguistics. volume 15. URL: http://repository. upenn.edu/pwpl/vol15/iss1/21.

Sheehan, M., Hinzen, W., 2011. Moving towards the edge. Linguistic Analysis 37, 405-458. 
Simons, M., 2007. Observations on embedding verbs, evidentiality, and presupposition. Lingua 117, 1034-1056. URL: http://www.sciencedirect.com/science/article/pii/S0024384106001288, doi:http://dx.doi.org/10.1016/j.lingua.2006.05.006.

Suñer, M., 2007. The syntax of direct quotes with special reference to Spanish and English. Natural Language \& Linguistic Theory 25, 655-655. URL: http://dx.doi.org/10.1007/s11049-007-9022-0, doi:10.1007/s11049007-9022-0.

Truckenbrodt, H., 2006. On the semantic motivation of syntactic verb movement to C in German. Theoretical Linguistics 32, 257-306. doi:10.1515/TL.2006.018.

Vikner, S., 1995. Verb Movement and Expletive Subjects in the Germanic Languages. Oxford University Press, Oxford.

Wechsler, S., 1991. Verb second and illocutionary force, in: Leffel, K., Bouchard, D. (Eds.), Views on Phrase Structure. Kluwer Academic Publishers, Dordrecht. volume 25 of Studies in Natural Language and Linguistic Theory, pp. 177 - 192.

Zanuttini, R., Portner, P., 2003. Exclamative Clauses: At the Syntax-Semantics Interface. Language 79, 39-81. doi:10.1353/lan.2003.0105. 